\title{
Prospecting the biodiversity of the fungal family Ustilaginaceae for the production of value-added chemicals
}

\author{
Elena Geiser, Vincent Wiebach, Nick Wierckx ${ }^{*}$ and Lars M Blank
}

\begin{abstract}
Background: Ustilaginaceae (belonging to the smut fungi) are commonly known for their plant pathogenicity. Although these microbes lead to yield reduction of cereal production, they can also have an economically positive side. Ustilaginaceae naturally produce a versatile range of value-added chemicals with potential applications in the food, pharmaceutical, and chemical industry.

Results: In this study 68 Ustilaginaceae of 13 species were screened for the production of organic acids, polyols, and glycolipids from glucose to characterize their biodiversity and identify potential novel strains for biocatalysis of these valuable chemicals. Ustilago cynodontis, Ustilago maydis, Ustilago avenae, and Sporisorium exsertum were identified as promising production organisms for itaconate, malate, succinate, and erythritol, respectively. The influence of buffer concentration $(\mathrm{pH})$ on acid production was investigated. Selected strains with best itaconate and malate production were characterized in more detail in bioreactor experiments obtaining total acid concentrations of up to $47 \pm 1 \mathrm{~g} \mathrm{~L}^{-1}$.

Conclusion: The identification and detailed characterization of these producers of valuable chemicals highlights the potential of these unicellular smut fungi for industrial applications and is a further step towards the biotechnological utilization of Ustilaginaceae.
\end{abstract}

Keywords: Ustilago maydis, Ustilaginaceae, Organic acid, Polyole, Glycolipid, Itaconate, Malate, Succinate, Erythritol

\section{Background}

The family Ustilaginaceae belongs to the order Ustilaginomycetes (true smut fungi) and contains 17 genera, such as Macalpinomyces, Sporisorium, Ustanciosporium, Pseudozyma, and Ustilago [1]. The entire family has described 607 species, including the model organism Ustilago maydis, which is mostly studied in relation to its plant pathogenicity. Members of the Ustilaginaceae can infect economically important crops including corn, barley, wheat, oats, sorghum, sugarcane, and forage grasses [2]. Symptoms they cause are tumor formation (Ustilago maydis) and phyllody in the inflorescences (Sporisorium reilianum) [3,4]. However, there are

\footnotetext{
* Correspondence: nick.wierckx@rwth-aachen.de

Chair of Applied Microbiology, iAMB - Institute of Applied Microbiology, ABBt - Aachen Biology and Biotechnology, Worringerweg 1, D-52074 Aachen, Germany
}

also non-pathogenic Ustilaginomycetes, such as Pseudozyma antarctica and Pseudozyma tsukubaensis.

Although these plant diseases lead to a considerable yield reduction of cereal production, smut fungi also have an economically positive side. They naturally produce a wide range of value-added chemicals (e.g. secondary metabolites, TCA cycle intermediates) with growing biotechnological interest. Reported metabolites are polyols, organic acids, extracellular glycolipids, iron-chelating siderophores and tryptophan derivatives [5,6]. Polyols, such as erythritol (ery) and mannitol, for example, have large markets as sweeteners for diabetics and as facilitating agents for the transportation of pharmaceuticals in medicine [7,8]. Itaconic (ita), L-malic (mal), succinic (suc), $l$-itatartaric (itt), and l-2-hydroxyparaconic (hp) acid are organic acids produced by many Ustilaginomycetes $[6,9]$. Applications for itaconic acid are for example the production of resins, plastics, adhesives, elastomers, coatings, and nowadays itaconate is discussed as a platform chemical in

\section{Biomed Central}

(c) 2014 Geiser et al.; licensee BioMed Central Ltd. This is an Open Access article distributed under the terms of the Creative Commons Attribution License (http://creativecommons.org/licenses/by/2.0), which permits unrestricted use, distribution, and reproduction in any medium, provided the original work is properly credited. The Creative Commons Public Domain Dedication waiver (http://creativecommons.org/publicdomain/zero/1.0/) applies to the data made available in this article, unless otherwise stated. 
the production of biofuels [10,11]. Malic acid is used in many food products, primarily as an acidulant [12]. Succinic acid is utilized as a precursor to pharmaceutical ingredients, such as additives, solvents, and polymers, but also as a food additive and dietary supplement [13]. Another category of metabolites produced by smut fungi contains extracellular glycolipids, such as mannosylerythritol lipids (mel) and ustilagic acid (ua) [14-16]. These lipids have biosurfactant properties and can be used in pharmaceutical, cosmetic, and food applications and are known for their strong fungicidal activity on many species [5].

Besides the production of this broad range of metabolites Ustilaginaceae have further positive characteristics. The haploid form of many strains grows unicellularly, which is advantageous in comparison to filamentous fungi where control of fungal morphology is an important process determinant [17]. Furthermore, the strains are able to metabolize a variety of poly- and monomers with carbohydrate origin derived from renewable non-food biomass degradation $[5,18,19]$, which are the substrates of choice for future biotechnological bulk production processes [20].

These advantages make strains of the family Ustilaginaceae promising candidates for industrial production of polyols, acids and lipids. So far large scale erythritol production by Pseudozyma tsukubaensis is the only reported industrial use of Ustilaginaceae, which is also a notable itaconate producer with up to $75 \mathrm{~g} \mathrm{~L}^{-1}$ itaconate $[8,9]$. While the fundamental biology of these species is studied in great detail, the biotechnological exploitation is still a relatively unexplored field. The production, as well as the ratio of the different products is strongly influenced by both the chosen strain and culture conditions $[6,21]$. To exploit nature's biosynthetic capabilities, 68 Ustilaginaceae of 13 species were screened for their production of itaconate, malate, succinate, erythritol, ustilagic acid, and mannosylerythritol lipids from glucose to characterize their biodiversity and identify potential novel strains for biocatalysis. High performing strains for the best itaconate and malate production were characterized in more detail in bioreactor experiments.

\section{Results and discussion}

Screening for best producer of itaconate, malate, succinate, erythritol, ustilagic acid, and mannosylerythritol lipids

For identification of potential novel strains for biocatalysis, 68 Ustilaginaceae of 13 species, with special focus on $56 U$. maydis strains, were cultivated in two different buffered, defined media and screened for their extracellular production of itaconate, malate, succinate, erythritol, and glycolipids. Table 1 and Figure 1 show an overview of the high biodiversity of products and their amounts. Raw data are provided in Additional file 1.

In the first $\mathrm{CaCO}_{3}$ buffered screening the strains showed a high variety of products and their amounts. Among the species $U$. maydis, the acid concentration differed highly, although the different strains generally produced the same products (Additional file 1, Figure 1). However, there were strains which stood out by their relatively high acid production. $U$. cynodontis 2217 was identified as the best itaconate producer with $3.3 \pm 0.1 \mathrm{~g} \mathrm{~L}^{-1}$ itaconate and a yield of $0.1 \pm 0.0 \mathrm{~g}_{\text {ita }} \mathrm{g}_{\text {glc }}^{-1}$ (Figure $1 \mathrm{~A}$ ). The best malate producer was $U$. maydis 2162 with $11.1 \pm 0.0 \mathrm{~g} \mathrm{~L}^{-1}$ malate and a yield of $0.3 \pm 0.0 \mathrm{~g}_{\mathrm{mal}} \mathrm{g}_{\text {glc }}^{-1}$ after $48 \mathrm{~h}$ cultivation (Figure 1B). The final malate titer of S. cruentum 2211 was in the same range with $11.0 \pm 0.0 \mathrm{~g} \mathrm{~L}^{-1}$ and a yield of $0.3 \pm 0.0 \mathrm{gmal}_{\mathrm{mal}} \mathrm{g}_{\mathrm{glc}}^{-1}$. However, the production rate was lower, because the highest malate titer was reached after $96 \mathrm{~h}$. Therefore, $U$. maydis 2162 was the preferred malate producer. The highest succinate concentration of $2.5 \pm 0.1 \mathrm{~g} \mathrm{~L}^{-1}$ was reached by $U$. avenae 2216 corresponding to a yield of $0.1 \pm 0.0 \mathrm{~g}_{\text {suc }} \mathrm{g}_{\text {glc }}^{-1}$ (Figure 1C). S. exsertum 2212 produced the highest amount of erythritol, namely $3.8 \pm 0.0 \mathrm{~g} \mathrm{~L}^{-1}$ with a yield of $0.1 \pm 0.0$ gery gglc (Additional file 1 , ery).

In addition, the variety and relative ratio of produced (glyco-) lipids amongst the tested genera and species differed considerably (Table 1 ). Because of the high variety of possible lipids for which no standards are available, the substances cannot be identified and quantified exactly. Therefore, the relative ratio was estimated by visual inspection of TLCs.

An additional screening in MES buffered screening medium was performed. MES is known for its significant impact on fungal metabolism [22,23]. Therefore, the influence of MES on growth and acid production of several representative strains of the family of Ustilaginaceae, was investigated using cultures with $\mathrm{MES}, \mathrm{CaCO}_{3}$, and a combination of both buffers. Neither growth nor acid production were negatively influenced by the presence of MES per se (data not shown). Therefore, MES was considered to be a suitable cultivation buffer. The MES buffered screening confirmed the best producer for itaconate, malate, and succinate (Additional file 1), although overall concentrations were generally lower than in $\mathrm{CaCO}_{3}$ buffered medium. Furthermore, the different buffer agents had a significant impact, especially on the mannosylerythritol lipids and ustilagic acid production. Additional file 1 (TLC) shows the TLC of extracted lipids produced by different Ustilaginaceae cultivated for $96 \mathrm{~h}$ in screening medium buffered with MES or $\mathrm{CaCO}_{3}$ exemplarily for 12 different strains. In cultivations with the stronger $\mathrm{CaCO}_{3}$ buffer none of the strains produced ustilagic acid and also less mannosylerythritol lipids were produced compared to the MES buffered cultivation (Additional file 1, TLC), indicating that extracellular lipids were preferentially produced at low $\mathrm{pH}$ values. An analytical effect of $\mathrm{CaCO}_{3}$ related to the precipitation of calcium salts of ustilagic acid was excluded by addition of $\mathrm{CaCO}_{3}$ 
Table 1 Overview of itaconate (ita), malate (mal), succinate (suc), erythritol (ery), ustilagic acid (ua), and mannosylerythritol lipids (mel)

\begin{tabular}{|c|c|c|c|c|c|c|c|c|}
\hline & \multirow{2}{*}{$\begin{array}{l}\text { ita } \\
\mathrm{C}\end{array}$} & \multirow{2}{*}{$\begin{array}{l}\text { mal } \\
\mathrm{C}\end{array}$} & \multirow{2}{*}{$\begin{array}{l}\text { ery } \\
\mathrm{C}\end{array}$} & \multirow{2}{*}{$\begin{array}{l}\text { suc } \\
\text { C }\end{array}$} & \multicolumn{2}{|c|}{$u^{a}{ }^{a}$} & \multicolumn{2}{|c|}{$\mathrm{mel}^{\mathrm{a}}$} \\
\hline & & & & & $\mathrm{C}$ & M & C & M \\
\hline Ustilago maydis $2162^{b}$ & ++ & ++++ & - & ++ & - & $*$ & - & - \\
\hline Macalpinomyces eriachnes 2209 & - & +++ & - & ++ & - & * & $* *$ & * \\
\hline Sporisorium consanguineum 2210 & - & + & + & ++ & - & - & - & - \\
\hline Sporisorium cruentum 2211 & - & ++++ & + & + & - & - & $* *$ & $* * *$ \\
\hline Sporisorium exsertum 2212 & - & ++ & +++ & + & - & - & $* /-$ & $* /-$ \\
\hline Sporisorium scitamineum 2213 & - & ++ & ++ & + & - & $* * *$ & - & $* * *$ \\
\hline Sporisorium walkeri 2214 & - & ++ & + & + & - & $* /-$ & - & - \\
\hline Ustanciosporium gigantosporum 2215 & - & + & - & - & - & - & - & * \\
\hline Ustilago avenae 2216 & - & + & - & ++ & - & - & - & - \\
\hline Ustilago cynodontis 2217 & +++ & + & ++ & + & - & - & - & - \\
\hline Ustilago filiformis 2218 & - & ++ & + & + & - & - & - & - \\
\hline Ustilago vetiveriae 2220 & + & ++ & - & + & - & - & - & - \\
\hline Ustilago xerochloae 2221 & + & + & + & + & - & - & - & - \\
\hline
\end{tabular}

Chemicals produced by several Ustilaginaceae after $96 \mathrm{~h}$ (malate after $48 \mathrm{~h}$ ) of cultivation in screening media buffered with $100 \mathrm{mM} \mathrm{MES} \mathrm{(} \mathrm{M}$ ) or $33 \mathrm{~g} \mathrm{~L}-1 \mathrm{CaCO}_{3}(\mathrm{C})$. $\left(-=\right.$ no production, $+=<1 \mathrm{~g} \mathrm{~L}^{-1},++=1-3 \mathrm{~g} \mathrm{~L}^{-1},+++=3-6 \mathrm{~g} \mathrm{~L}^{-1},++++=>6 \mathrm{~g} \mathrm{~L}^{-1}, * /-=$ no/low lipid production, ${ }^{*}=$ low lipid production, ${ }^{* *}=$ lipid production,

$* * *=$ high lipid production).

Strain numbers correspond to Additional file 1.

${ }^{a}$ no concentrations, relative ratio estimated from TLC.

${ }^{\mathrm{b}}$ Ustilago maydis 2162 was chosen as the best producer of itaconate, malate and succinate among all tested U. maydis strains.

to samples of MES buffered cultivations after $96 \mathrm{~h}$ resulting in the same TLC banding pattern as those of standard MES buffered cultivations (Additional file 1, TLC control). A similar $\mathrm{pH}$ sensitivity was already shown for the mannosylerythritol lipid production of Candida sp. strain SY16 using $\mathrm{pH}$ controlled fed-batch fermentations [24].

The screening confirmed the potential of the Ustilaginaceae to produce a wide range of biotechnologically interesting chemicals, if the selected strains are further optimized. After optimization they may compete with already published, better producing wildtype strains $[6,8,25]$.

An optimization strategy to find the best suitable candidate among the family Ustilaginaceae for industrial production of organic acid, such as itaconate, malate, and succinate, should contain the following four steps. First a species amongst the Ustilaginaceae needs to be identified, which produces the desired product as the main product with high yield. In the screening approach the different species showed a high variety of product combinations. However, there is still a huge biodiversity even among one species, such as Ustilago maydis. The results showed that the product spectrum between the $U$. maydis strains remained the same, whereas the concentrations of these products varied considerably, for instance $97 \%$ between the best and the worst itaconate producer. This leads to step two, which is the screening for an optimal producer of the desired product amongst one species covering a significant number of strains. Thirdly, the chosen strain can be further improved by metabolic engineering. Engineering of the strain may focus on the deletion of metabolic reactions leading to by-products, since for an industrial acid production the product spectrum of $U$. maydis is still too versatile. The most ideal outcome is one product with a high rate, yield, and titer preferably without any by-product [26]. First attempts have already been made by deleting the genes emt1 (um03117) and cyp1 (um11812) of $U$. maydis to disrupt the production of mannosylerythritol lipids and ustilagic acid [14,27]. Investigation of these knockouts in a biotechnological context would be a promising approach. Another engineering technique is the upregulation of pathways, which leads to the desired product - providing that these are known - for example by integration of stronger promoters to get higher expression of the involved genes [28]. The development of efficient genetic tools especially for $U$. maydis greatly facilitates these metabolic engineering efforts [29]. The last step is the optimization of the cultivation conditions for the product of choice. In former studies, the optimization of the cultivation process for itaconate with Aspergillus terreus for example successfully resulted in an increased production [10,30-39]. In the end this strategy leads to an optimized strain and process, engineered for one specific product, with high potential for industrial applications delivering contributions to a sustainable bioeconomy. 


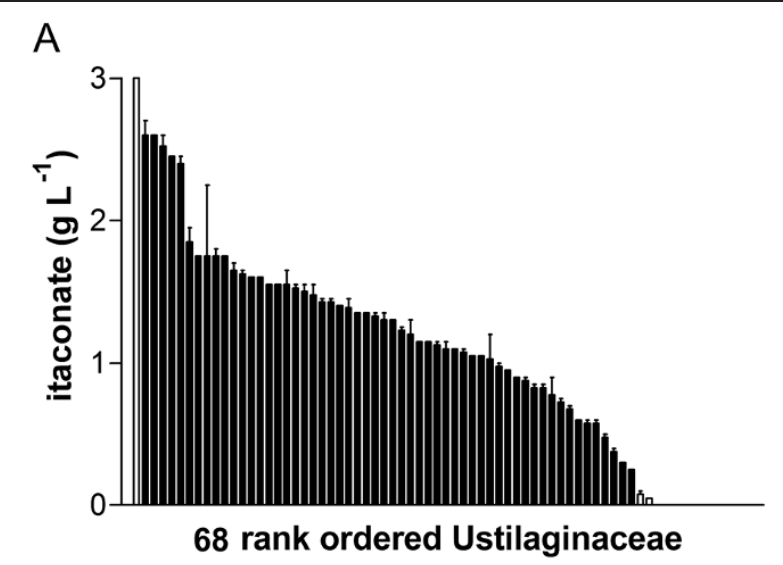

B

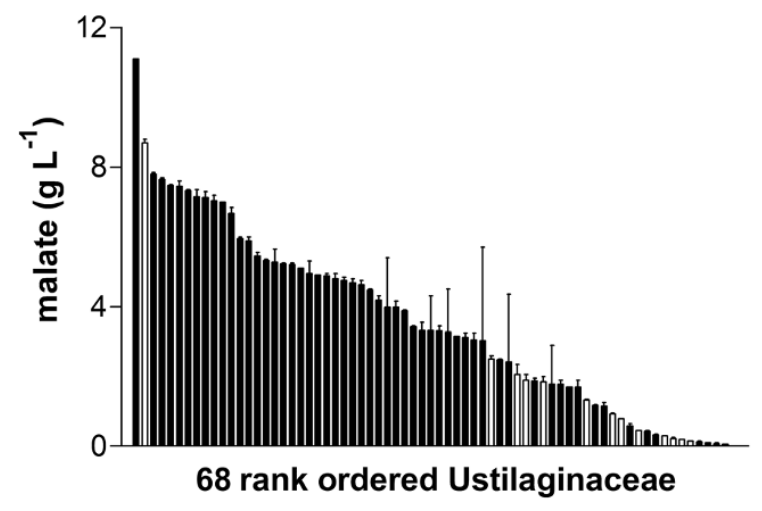

C

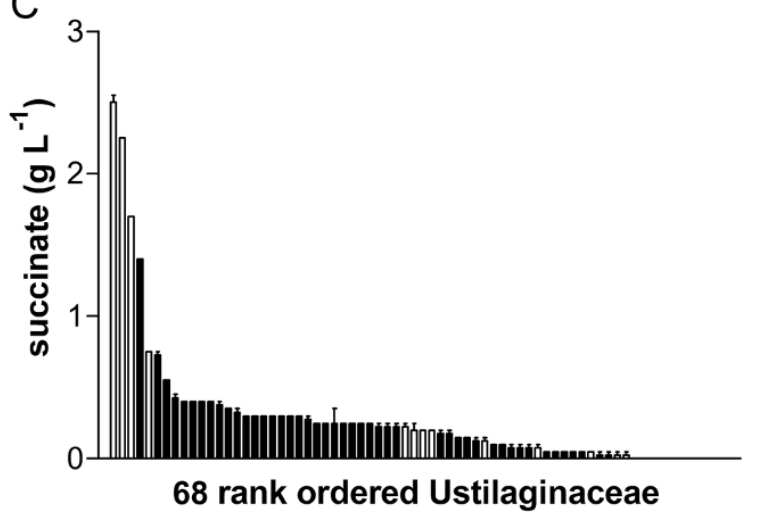

Figure 1 Overall biodiversity of different Ustilaginaceae. Concentration of itaconate (A), malate (B) and succinate (C) produced by different Ustilaginaceae were measured after $96 \mathrm{~h}$ (itaconate, succinate) or $48 \mathrm{~h}$ (malate) cultivation in $\mathrm{CaCO}_{3}$ buffered screening medium. Black bars are $U$. maydis strains, white bars other Ustilaginaceae. The values are the arithmetic mean of two biological determinations. Error bars indicate deviation from the mean. Strain numbers are available in Additional file 1.

\section{pH dependency}

Given the different results obtained in both screening buffers, the influence of $\mathrm{pH}$ on the metabolite production was further investigated. These investigations were performed in MES buffered screening media ( $\mathrm{pH}$ 6.5) with differing MES concentrations in a range from $30 \mathrm{mM}$ to $100 \mathrm{mM}$. For this, the strains $U$. maydis $2162, U$. maydis 2229, and $U$. cynodontis 2217 were chosen due to their high malate and itaconate production in the prior analysis. MES buffered cultures experience a gradual $\mathrm{pH}$ decrease as acids are produced, which continues until the $\mathrm{pH}$ minimum for acid production is reached. The rate of this decrease depends on the MES concentration. Therefore, the $\mathrm{pH}$ at the end of the culture, along with the dependency of the final acid concentration on the MES concentration, might be considered as a reflection of the $\mathrm{pH}$ minimum for acidic product formation.

The final $\mathrm{pH}$ after cultivation differed greatly between the three strains, while the different buffer concentrations had a much lower impact (Figure 2). The final $\mathrm{pH}$ of $U$. maydis 2229 was $5.3 \pm 0.2$, much higher than the final $\mathrm{pH}$ of $U$. maydis 2162 with $4.6 \pm 0.1$ and $U$. cynodontis 2217 with $3.3 \pm 0.5$, indicating a higher $\mathrm{pH}$ minimum of $U$. maydis 2229 and a lower $\mathrm{pH}$ limit for acid production of $U$. cynodontis. Generally, in $\mathrm{CaCO}_{3}$ buffered cultivations (Figure 1) or $\mathrm{pH}$-controlled batch fermentations (below) the produced acid concentrations were higher in comparison to them presented in Figure 2, confirming the general assumption that in most strains acid production is limited by the MES concentration.

Additionally, Figure 2 shows also the $\mathrm{pH}$ dependency of the itaconate, malate, succinate, mannosylerythritol lipids, and ustilagic acid production. U. maydis 2229 and $U$. maydis 2162 produced less itaconate and malate with decreasing buffer concentrations. Interestingly, the acid and erythritol production of $U$. cynodontis 2217 was entirely independent from the buffer concentration and hence from the $\mathrm{pH}$ value, indicating that the $\mathrm{pH}$ minimum is below the lowest measured value. A higher buffer capacity/concentration increases the titer of acids, and generally an excess of $\mathrm{CaCO}_{3}$ is used in shake flasks leading to a final $\mathrm{pH}$ ranging from 4 to 5 depending on the buffer concentration $[6,21,40,41]$. Assuming that the buffer influences the acid production, it is reasonable to investigate other buffers, such as MES, to consider the individual $\mathrm{pH}$ minimum/ optimum of each strain. Furthermore, this variation has to be confirmed by $\mathrm{pH}$ controlled batch fermentations. The erythritol production of $U$. maydis 2162 increased with decreasing buffer concentration, which was also ascertained by Guevarra and Tabuchi for $U$. cynodontis K320 in unbuffered media [40]. This metabolic change from acid production to polyole production is a common protective mechanism for microorganisms in case of pH stress [42].

The different minima can affect the upstream processes of the desired product. Depending on the upstream process conditions the best fitting and most suitable strain out of the broad spectrum can be chosen. For example, for simultaneous saccharification and fermentation (SSF) a $\mathrm{pH}$ of approximately 4.8 is preferred due to the $\mathrm{pH}$ 


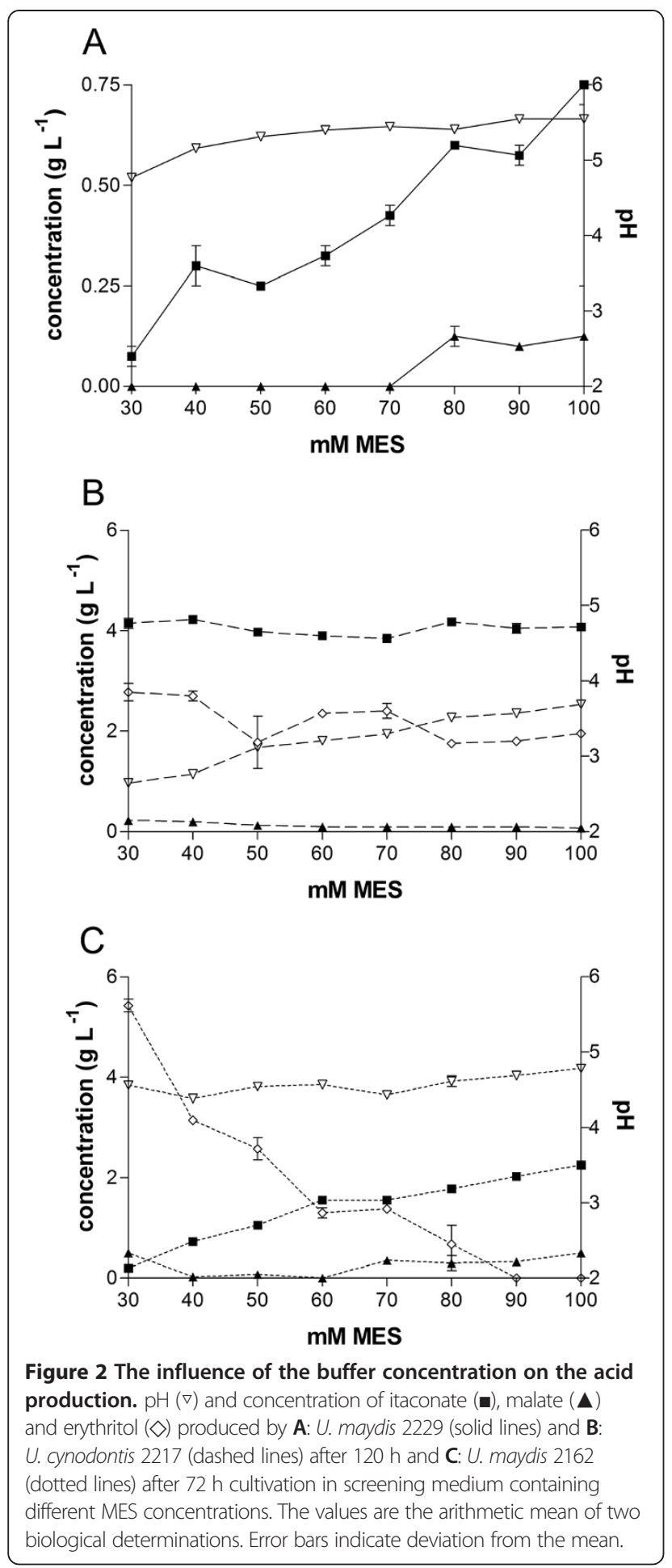

optima of the used cellulases [21,43]. This $\mathrm{pH}$ prerequisite would apply more for $U$. maydis 2229 or $U$. maydis 2162 , whereas $U$. cynodontis 2217 would be better for acid production in batch fermentations. Its low $\mathrm{pH}$ minimum facilitates the downstream processing because less base has to be added to back-titrate the stoichiometric amounts of produced acids, decreasing waste and costs, and therefore increasing the value.

The (glyco-) lipid production of $U$. maydis 2229 and $U$. maydis 2162 was also dependent on the buffer concentration (Table 2). With decreasing buffer concentration, $U$. maydis 2229 produced less mannosylerythritol lipids, $U$. maydis 2162 more. Also the ustilagic acid production of $U$. maydis 2229 increased with decreasing buffer concentration, whereas the ustilagic acid production of $U$. maydis 2162 remained constant.

\section{Controlled batch fermentation of the best itaconate and malate producer}

Although the buffer has a strong influence on the acid production, for industrial processes, additional parameters have to be investigated, preferably in controlled batch fermentations. To further characterize the production potential of Ustilaginaceae, two strains were chosen based on the following criteria: unicellular growth, best itaconate production, and best malate production. Even though $U$. cynodontis 2217 produced the highest amount of itaconate in the screening approaches in both $\mathrm{CaCO}_{3}$ and MES buffer, the strain was not used for further experiments because it displayed strong filamentous growth in stirred tank reactors, in comparison to single cell growth in System Duetz cultivations (Figure 3A and $\mathrm{C}$ ). The growth of the filamentous fungus on fermenter equipment, such as oxygen and $\mathrm{pH}$ electrodes, makes it inexpedient during batch fermentations and can pose additional costs [17]. So far it is still unclear what caused the change from unicellular to filamentous growth between shake-flask and stirred tank reactor growth. Possible causes include differences in shear forces caused by stirring and sparging, different oxygen supply and the presence of antifoam in the bioreactor. $U$. cynodontis' changing morphology depending on cultivation conditions was also observed by Zapata-Morín et al. [44] and DurieuTrautmann et al. [45].

Therefore, the two best performing under all cultivation conditions unicellular growing strains $U$. maydis 2229 and $U$. maydis 2162 were cultivated in controlled batch fermentation (Figure 3B and D). The nitrogen source in the $U$. maydis 2229 fermentation was exhausted after $18 \mathrm{~h}$ (Figure 4A), although further growth was observed after $\mathrm{N}$ depletion up to $58 \mathrm{~h}$. This phenomenon was previously seen and was related to intracellular lipid formation leading to swollen cells, and utilization of internal nitrogen pools for further reproduction cycles [21]. After $58 \mathrm{~h}$ the maximal cell dry weight (CDW) of $67 \pm 0 \mathrm{~g} \mathrm{~L}^{-1}$ was reached. In comparison to $U$. maydis 2229 the growth phase of $U$. maydis 2162 was longer, with depletion of the $\mathrm{N}$ source after $27 \mathrm{~h}$. After $58 \mathrm{~h}$ the maximal CDW of $62 \pm 0 \mathrm{~g} \mathrm{~L}^{-1}$ was observed. Glucose 
Table 2 Overview of mannosylerythritol lipids (mel) and ustilagic acid (ua) production by selected Ustilaginaceae

\begin{tabular}{|c|c|c|c|c|c|c|}
\hline \multirow[t]{2}{*}{ MES (mM) } & \multicolumn{2}{|c|}{ U. maydis 2229} & \multicolumn{2}{|c|}{ U. maydis 2162} & \multicolumn{2}{|c|}{ U. cynodontis 2217} \\
\hline & mel & ua & mel & ua & mel & ua \\
\hline 100 & ** & - & * & * & - & - \\
\hline 90 & $* *$ & - & * & * & - & - \\
\hline 80 & $* *$ & - & $* *$ & * & - & - \\
\hline 70 & $* *$ & - & $* *$ & * & - & - \\
\hline 60 & $*$ & * & $* *$ & * & - & - \\
\hline 50 & * & * & $* *$ & * & - & - \\
\hline 40 & * & * & $* *$ & * & - & - \\
\hline 30 & * & * & $* *$ & * & - & - \\
\hline
\end{tabular}

Samles were taken after $120 \mathrm{~h}$ of cultivation in screening media buffered with varying MES concentrations. (relative ratio estimated from TLC, $-=$ no lipid production, ${ }^{*}=$ low lipid production, ${ }^{* *}=$ lipid production).

was almost completely consumed at the end of both fermentations.

After nitrogen depletion, both strains produced a mix of itaconate, malate, and succinate (Figure 4B) as well as traces of an unknown product. The total acid concentrations were $35 \pm 4 \mathrm{~g} \mathrm{~L}^{-1}$ for $U$. maydis 2229 and $47 \pm 1 \mathrm{~g} \mathrm{~L}^{-1}$ for $U$. maydis 2162 . The strain $U$. maydis 2162 is the better malate producer and produced additionally the highest amount of succinate compared to $U$. maydis 2229 . However, the strain $U$. maydis 2229 produced the highest amount of itaconate in comparison to $U$. maydis 2162 . All production parameters are summarized in Table 3 . The addition of extra $100 \mathrm{~g} \mathrm{~L}^{-1}$ glucose at $72 \mathrm{~h}$ did not have a significant impact on acid production (data not shown).

The batch fermentations could confirm the product range found in the screening approaches, although published itaconate concentrations of $20-45 \mathrm{~g} \mathrm{~L}^{-1}$ produced by $U$. maydis 2229 under similar conditions could not be reached $[46,47]$. However, the obtained succinate concentration was in the range of published titers of $5 \mathrm{~g} \mathrm{~L}^{-1}$ produced by different Ustilago species [6]. For malate even higher concentrations were reached in comparison to the highest published concentrations of $20 \mathrm{~g} \mathrm{~L}^{-1}$ produced by $U$. maydis [6]. The maximal theoretical yields from glucose for itaconate, malate, and succinate are $0.7 \mathrm{~g}_{\text {ita }} \mathrm{g}_{\mathrm{glc}}^{-1}, 1.5 \mathrm{~g}_{\mathrm{mal}} \mathrm{g}_{\mathrm{glc}}^{-1}$, and $1.3 \mathrm{~g}_{\text {suc }} \mathrm{g}_{\mathrm{glc}}^{-1}$, respectively, assuming zero growth. These values are still far away from the measured values obtained in this study, indicating that there is still room for further optimization as mentioned in the previous section.

High formation of mannosylerythritol lipids, but no ustilagic acid, was also observed via TLC (data not shown). Additionally, both strains accumulated an unknown product during fermentation with an HPLC retention time of $12.4 \mathrm{~min}$ and an UV/RI area ratio of $4.5 \pm 0.3$ $\mathrm{mAU} \mathrm{mV}^{-1}$. Guevarra and Tabuchi proposed the appearance of $l$-itatartarate and $l$-2-hydroxyparaconate during itaconate production [40], with relative retention times to itaconate of $\mathrm{t}_{\mathrm{R} \text { (itt) }} / \mathrm{t}_{\mathrm{R} \text { (ita) }}=0.64$ and $\mathrm{t}_{\mathrm{R}(\mathrm{hp})} / \mathrm{t}_{\mathrm{R} \text { (ita) }}=0.78$,
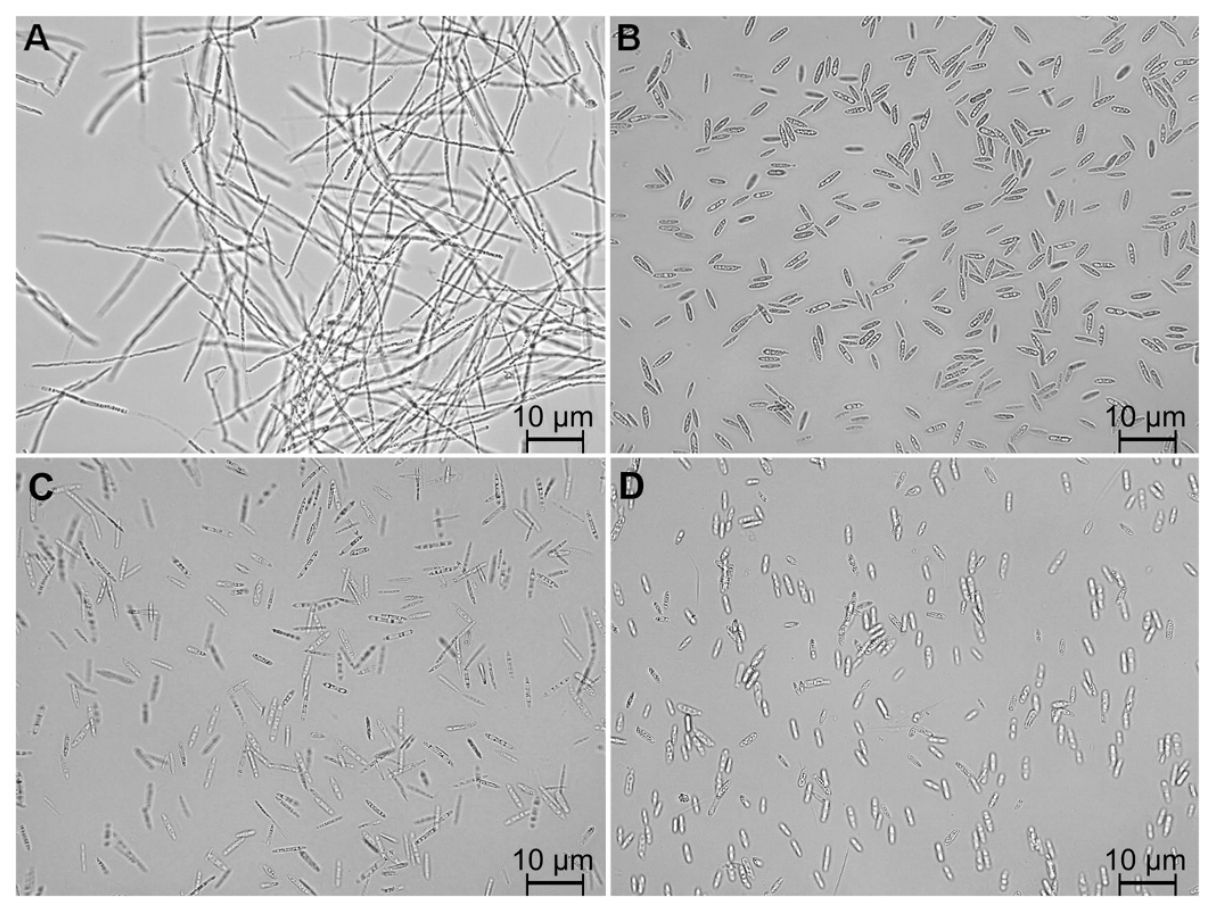

Figure 3 Light microscopy images of $U$. cynodontis 2217 (A, C) and $U$. maydis 2162 (B, D) cells. A and B: controlled batch fermentation in a bioreactor containing batch medium (200 g L-1 glucose, $4 \mathrm{~g} \mathrm{~L}^{-1} \mathrm{NH}_{4} \mathrm{Cl}, 30^{\circ} \mathrm{C}, 80 \% \mathrm{DOT}$, at $\mathrm{pH}$ 6.0). $\mathbf{C}$ and $\mathbf{D}$ : System Duetz cultivations containing screening medium (45.5 g L $\mathrm{glucose}^{-1} 0.8 \mathrm{~g} \mathrm{~L}^{-1} \mathrm{NH}_{4} \mathrm{Cl}, 33 \mathrm{~g} \mathrm{~L}^{-1} \mathrm{CaCO}_{3}, 30^{\circ} \mathrm{C}, 80 \%$ DOT, magnification 400X). 

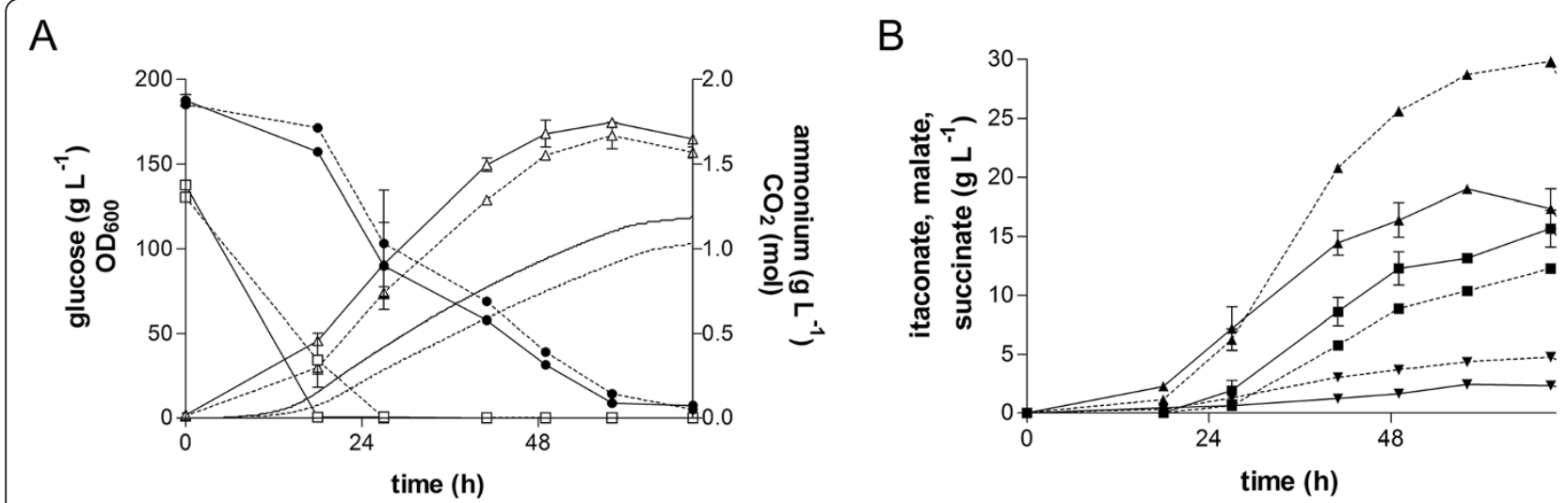

Figure 4 Controlled batch fermentation of the best itaconate and malate producers. $\mathbf{A}: \mathrm{OD}_{600}(\Delta)$, emitted $\mathrm{CO}_{2}$ amount (without symbols), concentration of glucose $(\bullet)$ and ammonium $(\square)$ and $\mathbf{B}$ : concentration of itaconate $(\mathbf{-})$, malate $(\boldsymbol{\Delta})$ and succinate $(\boldsymbol{\nabla})$ during fermentation in a bioreactor containing batch medium (200 g L $\mathrm{g}^{-1}$ glucose, $4 \mathrm{~g} \mathrm{~L}^{-1} \mathrm{NH}_{4} \mathrm{Cl}, 30^{\circ} \mathrm{C}, 80 \% \mathrm{DOT}$, at pH 6.0) with U. maydis 2229 (solid lines) and U. maydis 2162 (dotted lines). The values are the arithmetic mean of two biological determinations. Error bars indicate deviation from the mean. For the $\mathrm{CO}_{2}$ values, all deviations from the means were under $10 \%$.

respectively, measured by RI detector. The unknown product accumulated by both $U$. maydis strains during batch fermentations could possibly be $l$-2-hydroxyparaconate, since it has a relative retention time to itaconate of $t_{R \text { (unknown) }} / t_{R \text { (ita) }}=0.76$. However, this is yet to be confirmed since no standards are commercially available. $U$. maydis 2229 produced nearly twice as much of this unknown compound as $U$. maydis 2162 based on HPLC peak area using the RI detector (data not shown). Mass balancing accounted for $94.1 \pm 4.3 \%$ (U. maydis

Table 3 Production parameters of $U$. maydis 2229 and $U$. maydis 2162 bioreactor fermentations

\begin{tabular}{|c|c|c|c|}
\hline & & U. maydis 2229 & U. maydis 2162 \\
\hline \multirow[t]{3}{*}{ ita } & titer $\left(\mathrm{g} \mathrm{L}^{-1}\right)$ & $15.7 \pm 1.6$ & $12.2 \pm 0.4$ \\
\hline & $r_{p, \max }\left(g L^{-1} h^{-1}\right)^{c}$ & $0.48 \pm 0.03$ & $0.38 \pm 0.02$ \\
\hline & $\mathbf{Y}_{\mathbf{P} / \mathbf{S}}\left(g_{i t a} g_{g \mid c}^{-1}\right)^{d}$ & $0.08 \pm 0.01$ & $0.07 \pm 0.00$ \\
\hline \multirow[t]{3}{*}{ mal } & titer $\left(\mathrm{g} \mathrm{L}^{-1}\right)$ & $17.3 \pm 1.7$ & $29.9 \pm 0.5$ \\
\hline & $\mathbf{r}_{\mathbf{p}, \max }\left(g \mathrm{~L}^{-1} \mathrm{~h}^{-1}\right)^{c}$ & $0.52 \pm 0.21$ & $1.04 \pm 0.09$ \\
\hline & $\mathbf{Y}_{\mathrm{P} / \mathrm{S}}\left(\mathrm{g}_{\mathrm{mal}} \mathrm{g}_{\mathrm{g} \mid \mathrm{c}}^{-1}\right)^{d}$ & $0.09 \pm 0.01$ & $0.16 \pm 0.00$ \\
\hline \multirow[t]{3}{*}{ suc } & titer $\left(g L^{-1}\right)$ & $2.6 \pm 0.4$ & $4.8 \pm 0.1$ \\
\hline & $r_{p, \max }\left(g L^{-1} h^{-1}\right)^{c}$ & $0.04 \pm 0.02$ & $0.13 \pm 0.03$ \\
\hline & $\mathbf{Y}_{\mathbf{P} / \mathbf{S}}\left(\mathrm{g}_{\text {suc }} \mathrm{g}_{\mathrm{glc}}^{-1}\right)^{d}$ & $0.01 \pm 0.00$ & $0.03 \pm 0.00$ \\
\hline \multicolumn{2}{|c|}{$\mathbf{Y}_{\mathbf{P} / \mathbf{S}}\left(g_{\text {acid }} g_{g \mid c}^{-1}\right)^{e}$} & $0.19 \pm 0.01$ & $0.25 \pm 0.01$ \\
\hline \multicolumn{2}{|c|}{$\mathbf{Y}_{\mathbf{X} / \mathbf{S}}\left(g_{\text {biomass }} g_{\mathrm{glc}}^{-1}\right)^{f}$} & $0.36 \pm 0.01$ & $0.35 \pm 0.02$ \\
\hline \multicolumn{4}{|c|}{ 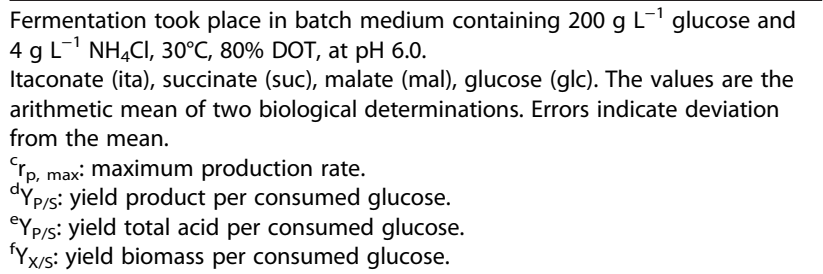 } \\
\hline
\end{tabular}

2229 ) and $93.8 \pm 0.9 \%$ ( $U$. maydis 2162 ) of the added carbon source, indicating that $0.19 \pm 0.14 \mathrm{Cmol}$ and $0.19 \pm 0.03 \mathrm{Cmol}$, respectively, were still unaccounted. This unaccounted fraction likely consists of (glyco-) lipids and/or the unknown product observed by HPLC. The unaccounted $0.19 \mathrm{Cmol}$ would correspond to approximately $11.7 \mathrm{~g} \mathrm{~L}^{-1} l$-2-hydroxyparaconate, $13.1 \mathrm{~g} \mathrm{~L}^{-1} l$-itatartarate, $6.8 \mathrm{~g} \mathrm{~L}^{-1}$ mannosylerythritol lipids or $8.3 \mathrm{~g} \mathrm{~L}^{-1}$ ustilagic acid or a mix of these products.

\section{Conclusions}

In summary this study demonstrates the potential of Ustilaginaceae for the production of value-added chemicals. From 68 Ustilaginaceae of 13 species, potential strains with favorable characteristics for the production of itaconate, malate, succinate, and erythritol from glucose were identified. The strains produced a broad range of products with varying concentrations showing the high biodiversity of this microbial family. Besides the product diversity there is also a variation in the $\mathrm{pH}$ minimum between the different strains and products, which can be exploited for alternative up- and downstream processes. In the future, this variation has to be confirmed by $\mathrm{pH}$ controlled batch fermentations. Furthermore, batch fermentations confirmed the product range found in the screening approaches and highlighted the importance of medium/ culture optimization, which combines the previously published biodiversity with new biotechnological aspects. Since Ustilaginaceae are able to use pentoses, such as xylose, which are components of non-food renewable biomass similar screening experiments on these carbon sources might also be conducted in the future. This high potential concerning the broad product spectrum of metabolites together with a unicellular growth pattern 
and the ability to utilize non-food renewable biomass as carbon source makes the Ustilaginaceae a promising family for the production of valuable chemicals.

\section{Methods}

Strains, media, and growth conditions

68 strains of the family Ustilaginaceae were used in this study (Additional file 1, strains). Numbers behind the species name indicate the strain number.

Screenings were performed in the System Duetz ${ }^{\circ}$ (24 well plates) with a filling volume of $1.5 \mathrm{~mL}$ (shaking diameter $=$ $50 \mathrm{~mm}$, agitation speed $=300 \mathrm{rpm}$, temperature $=30^{\circ} \mathrm{C}$, and relative air humidity $=80 \%$ ) [48]. The screening medium contained $45.5 \mathrm{~g} \mathrm{~L}^{-1}$ glucose, $0.8 \mathrm{~g} \mathrm{~L}^{-1} \mathrm{NH}_{4} \mathrm{Cl}$, $0.2 \mathrm{~g} \mathrm{~L}^{-1}$ $\mathrm{MgSO}_{4} \cdot 7 \mathrm{H}_{2} \mathrm{O}, 0.01 \mathrm{~g} \mathrm{~L}^{-1} \mathrm{FeSO}_{4} \cdot 7 \mathrm{H}_{2} \mathrm{O}, 0.5 \mathrm{~g} \mathrm{~L}^{-1} \mathrm{KH}_{2} \mathrm{PO}_{4}$, $1 \mathrm{~mL} \mathrm{~L}^{-1}$ vitamin solution, $10 \mathrm{~mL} \mathrm{~L}^{-1}$ trace element solution, and as buffer $33 \mathrm{~g} \mathrm{~L}^{-1}$ calcium carbonate $\left(\mathrm{CaCO}_{3}\right)$ or $19.5 \mathrm{~g} \mathrm{~L}^{-1}$ 2-(N-morpholino)ethanesulfonic acid (MES). The $\mathrm{pH}$ of the MES stock solution was adjusted to 6.5 with $\mathrm{NaOH}$. The vitamin solution contained (per liter) $0.05 \mathrm{~g}$ D-biotin, $1 \mathrm{~g}$ D-calcium panthotenate, $1 \mathrm{~g}$ nicotinic acid, $25 \mathrm{~g}$ myo-inositol, $1 \mathrm{~g}$ thiamine hydrochloride, $1 \mathrm{~g}$ pyridoxol hydrochloride, and $0.2 \mathrm{~g}$ para-aminobenzoic acid. The trace element solution contained (per liter) $1.5 \mathrm{~g}$ EDTA, $0.45 \mathrm{~g} \mathrm{ZnSO}_{4} \cdot 7 \mathrm{H}_{2} \mathrm{O}, 0.10 \mathrm{~g} \mathrm{MnCl}_{2} \cdot 4 \mathrm{H}_{2} \mathrm{O}, 0.03 \mathrm{~g}$ $\mathrm{CoCl}_{2} \cdot 6 \mathrm{H}_{2} \mathrm{O}, 0.03 \mathrm{~g} \mathrm{CuSO}_{4} \cdot 5 \mathrm{H}_{2} \mathrm{O}, 0.04 \mathrm{~g} \mathrm{Na}_{2} \mathrm{MoO}_{4} \cdot 2 \mathrm{H}_{2} \mathrm{O}$, $0.45 \mathrm{~g} \mathrm{CaCl}_{2} \cdot 2 \mathrm{H}_{2} \mathrm{O}, 0.3 \mathrm{~g} \mathrm{FeSO}_{4} \cdot 7 \mathrm{H}_{2} \mathrm{O}, 0.10 \mathrm{~g} \mathrm{H}_{3} \mathrm{BO}_{3}$, and $0.01 \mathrm{~g}$ KI. Samples were taken after $48 \mathrm{~h}$ and $96 \mathrm{~h}$, since initial experiments showed that the highest concentration of malate is reached by most of the strains after $48 \mathrm{~h}$ and carbon source is completely depleted after $96 \mathrm{~h}$ (data not shown).

Batch cultivations were performed in a New Brunswick BioFlo $^{\circ} 115$ bioreactor (Eppendorf, Germany) with a total filling volume of $1.3 \mathrm{~L}$ and a working volume of $0.5 \mathrm{~L}$. Cultivation conditions were chosen according to Maassen et al. [46]. All cultivations were performed in batch medium containing $200 \mathrm{~g} \mathrm{~L}^{-1}$ glucose, $4 \mathrm{~g} \mathrm{~L}^{-1} \mathrm{NH}_{4} \mathrm{Cl}$, $0.2 \mathrm{~g} \mathrm{~L}^{-1} \mathrm{MgSO}_{4} \cdot 7 \mathrm{H}_{2} \mathrm{O}, 0.01 \mathrm{~g} \mathrm{~L}^{-1} \mathrm{FeSO}_{4} \cdot 7 \mathrm{H}_{2} \mathrm{O}, 0.5 \mathrm{~g} \mathrm{~L}^{-1}$ $\mathrm{KH}_{2} \mathrm{PO}_{4}, 1 \mathrm{~g} \mathrm{~L} \mathrm{~L}^{-1}$ yeast extract (Merck Millipore, Germany), $1 \mathrm{~mL} \mathrm{~L}^{-1}$ vitamin solution, and $10 \mathrm{ml} \mathrm{L}^{-1}$ trace element solution. During cultivation, $\mathrm{pH} 6.0$ was maintained by automatic addition of $10 \mathrm{M} \mathrm{NaOH}$, and the dissolved oxygen tension (DOT) was kept constant above approximately $80 \%$ saturation by automatic adjustment of the stirring rate (700-1200 rpm). The bioreactor was aerated at a rate of $1 \mathrm{~L} \mathrm{~min}^{-1}(2 \mathrm{vvm})$. The temperature was set at $30^{\circ} \mathrm{C}$. Level sensor controlled antifoam 204 (Sigma Life Science, USA) was added to prevent foam formation. The bioreactor was inoculated to a final $\mathrm{OD}_{600}$ of 1.5 with cells from an overnight culture in $50 \mathrm{~mL}$ screening medium, which were washed two times with $0.9 \% \mathrm{NaCl}$. Bioreactor off-gas analysis for online monitoring of $\mathrm{CO}_{2}$ and $\mathrm{O}_{2}$ content were performed with
BlueInOne $_{\text {Ferm }}$ off-gas sensors (BlueSens gas sensor $\mathrm{GmbH}$ ). The online $\mathrm{CO}_{2}$ signal (\%) was converted into the absolute emitted $\mathrm{CO}_{2}$ amount in mol by multiplying the gas flow rate $\left(\mathrm{L} \mathrm{min}^{-1}\right)$ with the $\mathrm{CO}_{2}$ content (\%) and the molar volume of an ideal gas at 1 atmosphere of pressure and $25^{\circ} \mathrm{C}\left(\mathrm{L} \mathrm{mol}^{-1}\right)$. Mass balancing was achieved by subtracting the carbon amount of biomass, off-gas, and products, such as itaconate, malate, and succinate, from the substrate glucose.

\section{Analytical methods}

All values are the arithmetic mean of two biological determinations. Error bars or \pm -values indicate the deviation from the mean for two values.

Cell densities were measured by determining the absorption at $600 \mathrm{~nm}$ with a Unico spectrophotometer 1201.

For dry weight determination $3 \mathrm{~mL}$ culture broth was filtered using Macherey-Nagel Paper MN218B (MachereyNagel, Germany) and weighed after drying at $110^{\circ} \mathrm{C}$ for $24 \mathrm{~h}$.

Light microscopy images were taken with a Leica DM750 microscope with 400× magnification and a Leica ICC50 camera (Leica Microsystems GmbH, Wetzlar, Germany).

Glucose, itaconate, malate, succinate, and erythritol in the supernatants were analyzed in a Beckmann Coulter System Gold High Performance Liquid Chromatography (Beckmann Coulter $\mathrm{GmbH}$, Germany) with an Organic Acid Resin $300 \times 8 \mathrm{~mm}$ column (CS-Chromatography, Germany) and a differential refractometer LCD 201 (MELZ, Germany) or an UV detector Beckmann Coulter System Gold 166 Detector $(210 \mathrm{~nm}, 5 \mathrm{~Hz}$ ) (Beckmann Coulter $\mathrm{GmbH}$, Germany). As solvent, $5 \mathrm{mM} \mathrm{H}_{2} \mathrm{SO}_{4}$, with a flow rate of $0.6 \mathrm{~mL} \mathrm{~min}{ }^{-1}$ and a temperature of $30^{\circ} \mathrm{C}$, was used. All samples were filtered with Rotilabo ${ }^{\circ}$ syringe filters (CA, $0.20 \mu \mathrm{m}, \varnothing 15 \mathrm{~mm}$ ) and afterwards 1:5 diluted with $5 \mathrm{mM}$ $\mathrm{H}_{2} \mathrm{SO}_{4}$.

The ammonium concentration in the culture supernatant was measured by a colorimetric method according to Willis using salicylate and nitroprusside [49].

Glycolipids, such as mannosylerythritol lipids and ustilagic acid, were analyzed by thin-layer chromatography (TLC). Therefore, $0.6 \mathrm{~mL}$ ethyl acetate were added to $0.3 \mathrm{~mL}$ culture and mixed for $20 \mathrm{~min}$. After centrifugation $(14,000 \mathrm{~g}, 5 \mathrm{~min})$ the ethyl acetate phase was dried overnight at $70^{\circ} \mathrm{C}$ and resuspended in $50 \mu \mathrm{L}$ methanol. $5 \mu \mathrm{L}$ of extract were spotted on a TLC Silica gel 60 aluminum plate $(20 \mathrm{~cm} \times 20 \mathrm{~cm}$, Merck KGaA, Darmstadt Germany). A running buffer comprising $71 \%$ (v/v) chloroform, $28 \%(\mathrm{v} / \mathrm{v})$ methanol, and $1 \%(\mathrm{v} / \mathrm{v}) \mathrm{H}_{2} \mathrm{O}$ was used. For staining, the plate was sprayed with a mix of $97 \%(\mathrm{v} / \mathrm{v})$ acetic acid, $1 \%(\mathrm{v} / \mathrm{v}) p$-anisaldehyde, and $2 \%(\mathrm{v} / \mathrm{v}) \mathrm{H}_{2} \mathrm{SO}_{4}$ solution followed by $20 \mathrm{~min}$ of heating at $120^{\circ} \mathrm{C}$. All spots with a retardation factor $\left(\mathrm{R}_{\mathrm{f}}=\right.$ migration distance of the 
substance/migration distance of the solvent front) smaller than 0.62 were defined as ustilagic acid, everything else as mannosylerythritol lipids [50]. Brightness, color saturation, and contrast were modified in the TLC pictures to enhance visibility.

\section{Additional file}

Additional file 1: Provides the strain list and all raw data of the screenings in MES and in $\mathrm{CaCO}_{3}$ buffer including concentrations of itaconate, malate, erythritol, succinate, and relative amounts of mannosylerythritol lipids, ustilagic acid, and the unknown product. Additionally, an examplary TLC of extracted lipids produced by different Ustilaginaceae including an control TLC is provided.

\section{Competing interests}

The authors declare that there are no competing interests.

\section{Authors' contributions}

LMB and NW conceived and designed the study. EG and WW performed the experimental work. All authors interpreted experimental data. EG and NW wrote the manuscript. All authors read and approved the submission of the manuscript.

\section{Acknowledgements}

The authors gratefully acknowledge Michael Bölker and Ronny Kellner for providing many of the strains used in the screening. We also thank Sandra Wewetzer for advice on the TLC experiments, Hiroaki Kitazqwa (Toyoba LTD., Japan) for providing the TLC standard SurfMellow-B and Stephan Menzel and Guido Hennig for performing initial experiments. This work was performed as a part of the Cluster of Excellence "Tailor-Made Fuels from Biomass", which is funded by the Excellence Initiative of the German federal and state governments to promote science and research at German universities. Nick Wierckx was supported by the German Research Foundation through the Emmy-Noether program (Wi 4255/1-1).

Received: 31 January 2014 Accepted: 26 June 2014

Published online: 01 November 2014

\section{References}

1. Kirk PM, Ainsworth GC, Bisby GR: Ainsworth and Bisby's Dictionary of the Fungi. 10th edition. Wallingford: C.A.B. International; 2008.

2. Bakkeren G, Kämper J, Schirawski J: Sex in smut fungi: structure, function and evolution of mating-type complexes. Fungal Genet Biol 2008, 45:15-21.

3. Banuett F: Genetics of Ustilago maydis, a fungal pathogen that induces tumors in maize. Annu Rev Genet 1995, 29:179-208.

4. Ghareeb H, Becker A, Iven T, Feussner I, Schirawski J: Sporisorium reilianum infection changes inflorescence and branching architectures of maize. Plant Physiol 2011, 156(4):2037-2052.

5. Feldbrügge M, Kellner R, Schipper K: The biotechnological use and potential of plant pathogenic smut fungi. Appl Microbiol Biotechnol 2013, 97(8):3253-3265.

6. Guevarra ED, Tabuchi T: Accumulation of itaconic, 2-hydroxyparaconic, itatartaric, and malic acids by strains of the genus Ustilago. Agric Biol Chem 1990, 54(9):2353-2358.

7. Ikeda M, Bhattacharjee AK, Kondoh T, Nagashima T, Tamaki N: Synergistic effect of cold mannitol and $\mathrm{Na}^{+} / \mathrm{Ca}^{2+}$ exchange blocker on blood-brain barrier opening. Biochem Biophys Res Commun 2002, 291(3):669-674.

8. Moon HJ, Jeya M, Kim IW, Lee JK: Biotechnological production of erythritol and its applications. Appl Microbiol Biotechnol 2010, 86(4):1017-1025.

9. Aurich ADI, Barth GPD, Bodinus C, Kreyss E, Specht R: Process for the biotechnological production of itaconic acid. 2009, patent number DE102008011854 A1.

10. Willke T, Vorlop KD: Biotechnological production of itaconic acid. Appl Microbiol Biotechnol 2001, 56(3-4):289-295.

11. Geilen FMA, Engendahl B, Harwardt A, Marquardt W, Klankermayer J, Leitner $W$ : Selective and flexible transformation of biomass-derived platform chemicals by a multifunctional catalytic system. Angew Chem 2010, 122(32):5642-5646.
12. Tsao GT, Cao NJ, Du J, Gong CS: Production of multifunctional organic acids from renewable resources. In Recent Progress in Bioconversion of Lignocellulosics. Volume 65. Edited by Tsao GT, Brainard AP, Bungay HR, Cao NJ, Cen P, Chen Z, Du J, Foody B, Gong CS, Hall P, et al. Berlin Heidelberg: Springer; 1999:243-280. Advances in Biochemical Engineering/ Biotechnology.

13. Zeikus JG, Jain MK, Elankovan P: Biotechnology of succinic acid production and markets for derived industrial products. Appl Microbiol Biotechnol 1999, 51(5):545-552.

14. Bölker M, Basse CW, Schirawski J: Ustilago maydis secondary metabolism from genomics to biochemistry. Fungal Genet Biol 2008, 45:88-93.

15. Günther M, Hirth T, Zibek S, Rupp S: Produktion von Biotensiden mit Pseudozyma-Stämmen. BlOspektrum 2013, 19(7):813-815.

16. Morita T, Fukuoka T, Imura T, Kitamoto D: Production of glycolipid biosurfactants by basidiomycetous yeasts. Biotechnol Appl Biochem 2009, 53:39-49.

17. Kubicek $C P$, Punt $P$, Visser J: Production of Organic Acids by Filamentous Fungi. In Industrial Applications. Volume 10. Edited by Hofrichter M. Berlin Heidelberg: Springer; 2011:215-234. The Mycota.

18. Couturier M, Navarro D, Olive C, Chevret D, Haon M, Favel A, Lesage-Meessen L, Henrissat B, Coutinho PM, Berrin JG: Post-genomic analyses of fungal lignocellulosic biomass degradation reveal the unexpected potential of the plant pathogen Ustilago maydis. BMC Genomics 2012, $13: 57$.

19. Geiser E, Wierckx N, Zimmermann M, Blank LM: Identification of an endo-1,4-beta-xylanase of Ustilago maydis. BMC Biotechnol 2013, 13:59.

20. Gray KA, Zhao LS, Emptage M: Bioethanol. Curr Opin Chem Biol 2006, 10(2):141-146

21. Klement T, Milker S, Jäger G, Grande PM, de Maria PD, Büchs J: Biomass pretreatment affects Ustilago maydis in producing itaconic acid. Microb Cell Factories 2012, 11:43.

22. Giltrap NJ, Lewis DH: Inhibition of growth of ectomycorrhizal fungi in culture by phosphate. New Phytol 1981, 87(4):669-675.

23. Hilger $\mathrm{AB}$, Thomas $\mathrm{Kl}$, Krause $\mathrm{HH}$ : The effects of several buffers on growth and phosphorus nutrition of selected ectomycorrhizal fungi. Soil Biol Biochem 1986, 18(1):61-67.

24. Kim HS, Jeon JW, Kim BH, Ahn CY, Oh HM, Yoon BD: Extracellular production of a glycolipid biosurfactant, mannosylerythritol lipid, by Candida sp. SY16 using fed-batch fermentation. Appl Microbiol Biotechnol 2006, 70(4):391-396.

25. Magnuson JK, Lasure LL: Organic acid production by filamentous fungi. In Advances in fungal biotechnology for industry, agriculture and medicine. Edited by Tkacz JS, Lange L. New York: Kluwer Academic/Plenum Publishers; 2004:307-340.

26. Vickers CE, Blank LM, Kromer JO: Chassis cells for industrial biochemical production. Nat Chem Biol 2010, 6(12):875-877.

27. Hewald S, Linne U, Scherer M, Marahiel MA, Kämper J, Bölker M: Identification of a gene cluster for biosynthesis of mannosylerythritol lipids in the basidiomycetous fungus Ustilago maydis. Appl Environ Microbiol 2006, 72(8):5469-5477.

28. Teichmann B, Liu LD, Schink KO, Bölker M: Activation of the ustilagic acid biosynthesis gene cluster in Ustilago maydis by the $\mathrm{C}_{2} \mathrm{H}_{2}$ zinc finger transcription factor Rua1. Appl Environ Microbiol 2010, 76(8):2633-2640

29. Terfrüchte M, Joehnk B, Fajardo-Somera R, Braus GH, Riquelme M, Schipper K, Feldbrügge M: Establishing a versatile Golden Gate cloning system for genetic engineering in fungi. Fungal Genet Biol 2014, 62:1-10.

30. Okabe M, Lies D, Kanamasa S, Park EY: Biotechnological production of itaconic acid and its biosynthesis in Aspergillus terreus. Appl Microbiol Biotechnol 2009, 84(4):597-606.

31. Park YS, Itida M, Ohta N, Okabe M: Itaconic acid production using an air-lift bioreactor in repeated batch culture of Aspergillus terreus. J Ferment Bioeng 1994, 77(3):329-331.

32. Kautola H, Rymowicz W, Linko Y-Y, Linko P: Itaconic acid production by immobilized Aspergillus terreus with varied metal additions. App/ Microbiol Biotechnol 1991, 35(2):154-158.

33. Kautola H, Vahvaselkä M, Linko YY, Linko P: Itaconic acid production by immobilized Aspergillus terreus from xylose and glucose. Biotechnol Lett 1985, 7(3):167-172

34. Kautola H, Vassilev N, Linko YY: Continuous itaconic acid production by immobilized biocatalysts. J Biotechnol 1990, 13(4):315-323. 
35. Horitsu H, Takahashi Y, Tsuda J, Kawai K, Kawano Y: Production of itaconic acid by Aspergillus terreus immobilized in polyacrylamide gels. Eur J Appl Microbiol Biotechnol 1983, 18(6):358-360.

36. Yahiro K, Takahama T, Jai S, Park Y, Okabe M: Comparison of air-lift and stirred tank reactors for itaconic acid production by Aspergillus terreus. Biotechnol Lett 1997, 19(7):619-621.

37. Okabe M, Ohta N, Park YS: Itaconic acid production in an air-lift bioreactor using a modified draft tube. J Ferment Bioeng 1993, 76(2):117-122.

38. Kuenz A, Gallenmuller Y, Willke T, Vorlop KD: Microbial production of itaconic acid: developing a stable platform for high product concentrations. Appl Microbiol Biotechnol 2012, 96(5):1209-1216.

39. Hevekerl A, Kuenz A, Vorlop K-D: Filamentous fungi in microtiter plates-an easy way to optimize itaconic acid production with Aspergillus terreus. Appl Microbiol Biotechnol 2014, 1-7.

40. Guevarra ED, Tabuchi T: Production of 2-hydroxyparaconic and itatartaric acids by Ustilago cynodontis and simple recovery process of the acids. Agric Biol Chem 1990, 54(9):2359-2365.

41. Levinson WE, Kurtzman CP, Kuo TM: Production of itaconic acid by Pseudozyma antarctica NRRL Y-7808 under nitrogen-limited growth conditions. Enzym Microb Technol 2006, 39(4):824-827.

42. Hallsworth JE, Magan N: Culture age, temperature, and $\mathrm{pH}$ affect the polyol and trehalose contents of fungal propagules. Appl Environ Microbiol 1996, 62(7):2435-2442.

43. Jäger G: Biocatalytic conversion of cellulose towards itaconic acid, Dissertation. Rheinisch-Westfälische Technische Hochschule Aachen; 2012.

44. Zapata-Morín PA, Fuentes-Dávila G, Adame-Rodríguez JM, Aréchiga-Carvaja ET: Effect of $\mathrm{pH}$ and carbon source on the vegetative growth of Ustilago cynodontis (Pass.) Henn. in a solid and liquid culture medium. Revista Mexicana de Fitopatología 2010, 28(2):159-161.

45. Durieu-Trautmann O, Tavlitzki J: Reversible and permanent effects of the carbon sources and various antibiotics on the morphology and metabolic properties of Ustilago cynodontis cells. J Cell Biol 1975, 66(1):102-113.

46. Maassen N, Panakova M, Wierckx N, Geiser E, Zimmermann M, Bölker M, Klinner U, Blank LM: Influence of carbon and nitrogen concentration on itaconic acid production by the smut fungus Ustilago maydis. Eng Life Sci 2013, 14(2):129-134.

47. Klement T, Büchs J: Itaconic acid - a biotechnological process in change. Bioresour Technol 2013, 135:422-431.

48. Duetz WA, Ruedi L, Hermann R, O'Connor K, Büchs J, Witholt B: Methods for intense aeration, growth, storage, and replication of bacterial strains in microtiter plates. Appl Environ Microbiol 2000, 66(6):2641-2646.

49. Willis RB, Montgomery ME, Allen PR: Improved method for manual, colorimetry determination of total Kjeldahl nitrogen using salicylate. J Agric Food Chem 1996, 44(7):1804-1807.

50. Teichmann B: The cellobiose lipid ustilagic acid from Ustilago maydis: biosynthesis and transcriptional regulation, Dissertation. Philipps University Marburg; 2009 .

doi:10.1186/s40694-014-0002-y

Cite this article as: Geiser et al.: Prospecting the biodiversity of the fungal family Ustilaginaceae for the production of value-added chemicals. Fungal Biology and Biotechnology 2014 1:2

\section{Submit your next manuscript to BioMed Central and take full advantage of:}

- Convenient online submission

- Thorough peer review

- No space constraints or color figure charges

- Immediate publication on acceptance

- Inclusion in PubMed, CAS, Scopus and Google Scholar

- Research which is freely available for redistribution 